\title{
Agariya Vinaya, Sanksi dan Implementasinya bagi umat Buddha
}

\author{
Warsito \\ STABN Sriwijaya Tangerang Banten \\ warsitosuranata79@gmail.com
}

\begin{abstract}
ABSTRAK
Sila sebagai landasan moral bagi pelaksanaan Dhamma selanjutnya merupakan hukum yang jika ditaati akan membawa kebaikan dan jika tidak ditaati akan menyebabkan manusia tidak dapat maju kualitas batinnya. Namun para pengikut Sang Buddha terdiri dari dua macam yaitu para Gharavasa (umat perumah tangga) dan Pabbajita (para pertapa). Oleh karena itu Sang Buddha menetapkan peraturan yang berbeda bagi keduanya. Peraturan moral bagi para perumah tangga dikenal sebagai Sila sedangkan peraturan bagi para bhikkhu dikenal sebagai Vinaya, meski sebenarnya keduanya adalah Vinaya. Sila mempunyai banyak arti. Pertama, berarti norma (kaidah), peraturan hidup, perintah, Kedua, kata itu menyatakan pula keadaan batin terhadap peraturan hidup, hingga dapat berarti juga sikap, keadaban, perilaku, sopan-santun dan sebagainya.

Ciri dari sila adalah ketertiban dan ketenangan. Dalam agama Buddha, sila merupakan dasar utama dalam pelaksanaan ajaran agama, mencakup semua perilaku dan sifat-sifat baik yang termasuk dalam ajaran moral dan etika agama Buddha. Penyebab terdekat sila adalah Hiri dan Otappa. Sila sebagai latihan moral bagi umat awam (Gharavasa) terdiri dari berbagai macam jenis. Berdasarkan aspeknya yaitu varita-sila (aspek negatif), yaitu sila yang dilakukan dengan cara 'menghindari', terdiri dari: Pancasila Buddhis, Atthasila, Dasasila, carita-sila (aspek positif), yaitu sila yang dilakukan dengan cara 'melakukan", terdapat dalam sutta-sutta misalnya: Vyagghapajja Sutta, Maha Manggala Sutta, Sigalovada Sutta, Parabhava Sutta.

Agariya Vinaya adalah peraturan untuk umat Buddha Buddha yang berkeluarga meliputi Pancasila, Atthangasila (uposathasila) dan Dasasila. Pengertian yang lebih sempit vinaya perumahtangga adalah Pancasila Buddhis. Pengembangan Pancasila Buddhis dilakukan dengan melaksanakan Panca Dhamma. Sila untuk umat berkeluarga bersifat moral semata dan digolongkan Pakati Sila. Berbeda dengan sila untuk para Bhikhu yang ditambah dengan hukuman yang dikeluarkan oleh Sangha. Setiap pelanggaran yang dilakukan Gharavasa berupa sanksi moral dari masyarakat tempat tinggal, misalnya: diusir dari daerah tersebut, dikucilkan dan lain-lain. Bila pelanggaran itu termasuk kategori berat (misalnya membunuh atau mencuri) maka pelaku dapat dikenakan sanksi oleh pemerintah dimana ia tinggal. Namun pelanggaran apapun yang dilakukan oleh seorang Gharavasa tidak akan menyebabkan ia dikeluarkan dari statusnya sebagai Gharavasa.
\end{abstract}

Kata kunci: Agariya Vinaya, Sanksi, Umat Buddha 


\begin{abstract}
Sila as the moral foundation for the implementation of the Dhamma is further a law which if obeyed will bring goodness and if not obeyed will cause man can not advance his inner qualities. But the followers of the Buddha are of two kinds: the Gharavas (the householder) and the Pabbajita (the ascetics). Therefore the Buddha set different rules for both. The moral rules for the householders are known as Sila while the rules for monks are known as Vinaya, though in fact both are Vinaya. Sila has many meanings. First, it means norms (rules), rules of life, commands. Second, it also states the inner state of the living order, which can mean 'attitude, civilization, behavior, manners' and so on.

The hallmark of the precepts is order and tranquility. In Buddhism, precepts are the primary basis for the implementation of religious teachings, encompassing all the attitudes and qualities that belong to the moral and ethical teachings of Buddhism. The nearest cause of precepts is Hiri and Otappa. Sila as a moral exercise for the laity (Gharavasa) consists of various types. Based on the aspect of the sila (negative aspect), the precepts done by 'avoiding', consist of: Pancasila Buddhis, Atthasila, Dasasila, carita-sila (positive aspect), ie sila done by way of 'doing' in the suttas for example: Vyagghapajja Sutta, Maha Manggala Sutta, Sigalovada Sutta, Parabhava Sutta.

Agariya Vinaya is a regulation for Buddhist Buddhists whose families include Pancasila, Atthangasila (uposathasila) and Dasasila. The narrower meaning of the household vinaya is the Buddhist Pancasila. The development of Buddhist Pancasila is done by implementing the Panca Dhamma. The precepts for mankind are mere moral and classified Pakati Sila. In contrast to the precepts for the monks coupled with the punishment issued by the Sangha. Any violation committed Gharavasa in the form of moral sanctions from the resident community, for example: expelled from the area, ostracized and others. If the offense is categorized as severe (such as killing or stealing) then the offender may be subject to sanction by the government in which he / she resides. But any offense committed by a Gharavasa will not cause him to be expelled from his status as Gharavasa.
\end{abstract}

Keywords: Agariya Vinaya, Sanctions, Buddhists

\title{
Pendahuluan
}

Dalam beberapa kejadian, banyak orang yang berbuat semaunya sendiri tanpa mempertimbangkan baik dan buruk perbuatan yang dilakukan. Akibat yang ditimbulkan apakah akan merugikan bagi orang lain atau tidak tidak dipersoalkan. Kemajuan dalam berbagai bidang komunikasi maupun informasi dan teknologi memberikan andil dalam munculnya masalah moral. Banyak orang tidak lagi memiliki pegangan tentang norma kehidupan dan norma kesopanan. Norma-norma dalam kehidupan memiliki peran yang penting dalam pembentukan kehidupan yang bahagia. Pada prinsipnya moral itu di mulai dari diri pribadi sejak dini, dengan pemahaman moral yang baik akan mengurangi kemerosotan moral dalam kehidupan sehari-hari sehingga tercipta kedamaian, kesejahteraan dan keharmonisan dalam kehidupan masyarakat dan negara. Kemudahan-kemudahan yang didapat dalam perkembangan teknologi membawa 
dampak negatif terhadap keberadaan moral dan etika yangmulai dilupakan. Upaya mengatasi kemerosotan moral menurut pandangan agama Buddha perlu dilakukan dengan mengembangkan perilaku yang baik dalam kehidupan sehari-hari.

Sila berasal dari bahasa Pāḷ. Definisi dari sila adalah alat bantu yang digunakan seseorang untuk dapat mempunyai sikap atau perilaku atau tindakan yang baik, yang bagus, yang murni, atau yang tidak tercela. Sila dapat juga dikatakan sebagai alat pengendali yang digunakan agar terhindar dari perbuatan dan ucapan yang tidak terpuji. Sila berada pada posisi kedua dalam tiga landasan perbuatan berjasa (puñ̃na-kiriya-vatthu). Dana (dāna), sila atau moralitas (sīla), dan pengembangan mental/meditasi (bhāvanāa) atau bila diuraikan lebih detil menjadi sepuluh perbuatan berjasa. Definisi yang lebih mendalam, berdasarkan Paṭisambhidāmagga, sila adalah kehendak hati (cetana), sila adalah faktor mental (cetasika), sila adalah pengendalian/pengekangan (samvvara), dan sila adalah tanpa-pelanggaran1. Walaupun hal ini ditujukan kepada bhikkhu, tetapi para umat juga dapat mengadopsi dan mengimplementasikannya sampai batasan tertentu.

\section{Pembahasan}

Sila adalah cetana yaitu cetana yang berada pada orang yang menghindari perbuatan dan ucapan salah yakni : 1) Membunuh (pāṇātipātāa), 2) Mencuri-mengambil barang yang tidak diberikan (adinnādānā) 3) Melakukan perbuatan asusila melakukan hubungan seksual bukan dengan pasangannya (istri/ suami). Pria tidak boleh melakukan hubungan seksual dengan wanita yang masih berada dalam lindungan: ibu, ayah, saudara laki-laki, saudara perempuan, kerabat, dan yang telah bersuami, yang mengakibatkan mendapatkan hukuman, dan yang telah bertunangan (kāmesu-micchācārā). Terdapat empat ucapan yang tidak terpuji:

\section{Berbohong}

Tidak tahu mengatakan tahu, tahu mengatakan tidak tahu, belum melihat mengatakan telah melihat, telah melihat mengatakan belum melihat. Seseorang dapat melakukan hal ini demi dirinya sendiri, demi orang lain, atau demi mendapatkan hadiah/sesuatu (musāvādā).

2. Memfitnah/mengadu domba

Apa yang didengarnya di sini, dia katakan di sana untuk memisahkan mereka yang di sana dengan mereka yang di sini atau sebaliknya; sehingga, membuat mereka yang bersatu menjadi terpecah dan meningkatkan perselisihan bagi yang telah terpecah. Ia menyukai, menyenangi pembicaraan yang membuat terjadinya perselisihan/perpecahan (pisunavācā). 


\section{Bicara kasar}

Perkataan yang: memicu munculnya kemarahan dan tidak kondusif untuk terjadinya

konsentrasi; serta kata-kata marah: yang tajam, menusuk, keras (pharusāvācā).

4. Gosip, bicara yang tidak bermanfaat

Ppembicaraan yang tidak tepat waktunya, tidak berdasarkan fakta, dan tidak sesuai dengan

Dhamma dan Vinaya (samphappalāpa).

Sila adalah faktor mental (cetasika) yaitu tiga cetasika penghindaran (virati) yaitu bicara benar (sammāâācā), perbuatan benar (sammākammanta), dan penghidupan benar (sammāa-àjīva). Bicara benar adalah menghindari bicara salah dan perbuatan benar adalah menghindari perbuatan salah, sama seperti definisi pada penjelasan sila sebagai cetana. Penghidupan benar adalah menghindari lima macam perdagangan:

1. Berdagang minuman keras (termasuk juga obat-obatan terlarang).

2. Berdagang racun.

3. Berdagang senjata.

4. Berdagang manusia.

5. Berdagang daging (hewan untuk dibunuh, diambil dagingnya).

Pengendalian dengan kesabaran: berusaha bersabar dalam menghadapi segala situasi, misalnya seorang bhikkhu harus bersabar dalam menghadapi cuaca panas dan dingin. Pengendalian dengan usaha: seorang bhikkhu harus mengerahkan usaha (viriya) untuk menghindari atau menghentikan kilesa dan mempertahankan serta mengembangkan perbuatan baik yang sudah ada contohnya, saat ada keserakahan muncul, maka harus berusaha secepatnya untuk memadamkan keserakahan tersebut. Selain itu seorang bhikkhu juga harus berusaha mendapatkan kebutuhannya dengan cara yang benar, misalnya mendapatkan makanan dengan berkeliling mengumpulkan dana makanan (piṇdapāta), tidak boleh meminta (bila tidak ada yang memberi) kecuali sedang sakit; membuat jubah dari kain yang telah dibuang (bila tidak ada yang memberi). Tidak boleh mencari uang, melakukan ramalan, praktik pengobatan (kecuali pada orang tua atau saudara sedarah), dll.

Sila adalah tanpa-pelanggaran yaitu tidak melakukan pelanggaran melalui perbuatan ataupun ucapan terhadap peraturan yang sedang dijalani. Sila dapat dijalankan oleh semua orang, mulai dari anak-anak sampai orang tua. Semakin baik silanya, maka orang tersebut akan semakin baik perilaku dan kepribadiannya. Selain itu, dapat dipastikan akan semakin banyak orang yang menyenangi dan mengaguminya. Mengenai tempat penggunaan juga tidak ada 
batasannya, sila cocok digunakan di segala tempat, dari tempat yang ramai sampai tempat yang sepi, bahkan di hutan sekalipun. Hal ini dapat dilihat dari kisah-kisah kehidupan para bhikkhu yang terdapat di sutta-sutta, dapat terlihat jelas bahwa mulai dari rakyat kecil yang tinggal di desa terpencil sampai dengan raja yang tinggal di istana yang megah di ibu kota kerajaan yang ramai dan padat, semuanya memberikan penghormatan kepada bhikkhu. Saat ini, hal ini masih sangat mudah untuk ditemukan, khususnya di negara-negara Buddhis seperti Myanmar, Thailand, Kamboja, dll. Jalan Mulia Beruas Delapan adalah jalan yang harus ditempuh oleh semua orang yang ingin tercerahkan. Jalan Mulia ini terdiri dari tiga kelompok, yaitu sila atau moralitas (sīla), konsentrasi (samādhi), dan kebijaksanaan (paññā). Kelompok sila terdiri dari ucapan benar (sammā̄ $\bar{a} c \bar{a})$, perbuatan benar (sammākammanta), dan penghidupan benar (sammā-äjīva), dan hal ini merupakan landasan dasar (pertama atau utama) dalam Jalan Mulia Beruas Delapan. Tanpa sila yang baik dan mantap, konsentrasi dan kebijaksanaan tidak dapat diharapkan untuk tumbuh dan berkembang menjadi sempurna. Hal ini bagaikan rumah yang fondasinya rapuh tidak akan dapat berdiri dengan kokoh.

Dalam Kimatthiya Sutta, Sang Buddha menerangkan tentang pahala dan berkah dari sila kepada bhante Ānanda. Yang Mulia, apakah pahala dan berkah dari moralitas yang baik (kusala sīla)? Ānanda, bebas dari penyesalan (avippațisāra) adalah pahala dan berkah dari moralitas yang baik. Yang Mulia, apakah pahala dan berkah dari bebas dari penyesalan? Ānanda, rasa senang (pāmojja) adalah pahala dan berkah dari bebas dari penyesalan. Yang Mulia, apakah pahala dan berkah dari rasa senang? Ānanda, kegiuran ( $p \bar{\imath} t i)$ adalah pahala dan berkah dari rasa senang. Ketenangan (passaddhi) adalah pahala dan berkah dari kegiuran Kebahagiaan (sukha) adalah pahala dan berkah dari ketenangan. Konsentrasi (samādhi) adalah pahala dan berkah dari kebahagiaan. Melihat dan mengetahui sesuatu sebagaimana adanya (yathābhūtañānadassanaṃ) adalah pahala dan berkah dari konsentrasi. Pembalikan arah (muak) dan hilangnya nafsu (nibbidāvirāgo) adalah pahala dan berkah dari melihat dan mengetahui sesuatu sebagaimana adanya. Melihat dan mengetahui jalan menuju pencerahan (vimuttiñānadassana) adalah pahala dan berkah dari pembalikan arah (muak) dan hilangnya nafsu. Berdasarkan sutta di atas dapat dilihat dengan jelas bahwa sila adalah landasan dari konsentrasi dan kebijaksanaan. Oleh karena itu, sila adalah landasan utama dari Jalan Mulia Beruas Delapan. Siapapun yang ingin tercerahkan harus berlatih Jalan Mulia Beruas Delapan. Dengan demikian, dia yang ingin tercerahkan harus melaksanakan dan menjaga silanya dengan baik; bagaikan ayam yang menjaga telur-telurnya; bagaikan seseorang yang menjaga mata satu-satunya.bagaikan seorang ibu yang menjaga anak satu-satunya. Dapat melaksanakan dan menjaga sila dengan baik adalah 
sesuatu yang sangat berharga. Agar hal tersebut dapat dicapai, maka pelaksana sila sebaiknya mengetahui tentang karakteristik atau sifat, fungsi, manifestasi, dan sebab dari sila.

Karakteristik dari sila adalah mengoordinasi tindakan jasmani dan ucapan, dan sebagai dasar bagi keadaan yang menguntungkan. Fungsi dari sila adalah mencegah terjadinya tindakan buruk atau menghentikan tindakan buruk yang sedang terjadi. Selain itu, sila juga berfungsi untuk membantu tercapainya kualitas tanpa cela. Manifestasi dari sila adalah kemurnian dalam tindakan jasmani dan ucapan, dan sebab terdekatnya adalah rasa malu untuk melakukan tindakan tidak terpuji (hiri) \& rasa takut akan akibat tindakan tidak terpuji (ottappa). Apakah ada sebab lain yang menjadikan seseorang untuk melaksanakan sila? Ya. Sebagai contoh, seorang anak kecil yang belum mengetahui perbedaan antara perbuatan baik dan buruk, melaksanakan sila karena diharuskan oleh orang tuanya.

Hiri adalah cetasika yang merupakan lawan dari ahirika. Cetasika inilah yang membuat seseorang merasa malu untuk melakukan tindakan tidak terpuji; oleh karena itu, dia akan berusaha untuk menghormati dan menjaga harga dirinya. Pada seseorang yang memiliki rasa malu (hiri), akan muncul perasaan malu dan perenungan terhadap tindakan tidak terpuji yang akan dilakukannya. Bila hiri-nya kuat, dia kemungkinan besar dapat menghindari perbuatan tidak terpuji yang akan dilakukannya. Apa jadinya bila mereka mengetahui bahwa saya adalah seorang koruptor? Mau diletakkan di mana muka saya ini?” Seseorang juga dapat merenungkan tentang status pendidikannya, jabatannya, umurnya, dll. Contohnya, "Semua orang mengetahui saya sebagai orang yang berpendidikan. Apa jadinya bila mereka mengetahui bahwa saya melakukan tindakan yang tidak terpuji ini?"

Ottappa adalah cetasika yang merupakan lawan dari anottappa. Cetasika inilah yang membuat seseorang merasa takut untuk melakukan tindakan tidak terpuji, karena takut akan akibat dari perbuatan tidak terpuji yang akan dilakukannya. Seseorang yang memiliki ottappa, akan mempertimbangkan kehormatan orang lain yang dekat dengannya (seperti orang tua, sanaksaudara, guru, teman-temannya, dll.) dan akan berusaha untuk tidak menyebabkan nama mereka ikut tercemar oleh perbuatan bodohnya. Misalnya, "Bila saya melakukan perbuatan tidak terpuji, maka semua anggota keluarga juga ikut tercemar namanya.

Sila dapat diklasifikasikan menjadi bermacam-macam kategori. Berdasarkan penjelasan yang terdapat di Visuddhimagga, sila diklasifikasikan menjadi sembilan belas macam kategori (VM I,25). Diantaranya adalah sila berdasarkan rentang waktu pelaksanaannya yaitu sementara 
dan seumur hidup; berdasarkan tingkatannya yaitu rendah, sedang, dan tinggi; duniawi dan adiduniawi. Namun di sini, hanya akan dibahas secara garis besar beberapa macam sila yang telah dikenal secara umum di masyarakat, yaitu: lima-sila (pañcasīla), delapan-sila (ațthasīla), sepuluh-sila (dasasīla), dan sila untuk bhikkhu.

\section{Lima-Sila (Pañcasīla)}

Pañcasīla atau lima-sila ini adalah sila yang seharusnya dilaksanakan oleh semua orang, bukan hanya oleh umat beragama Buddha (upāsaka dan upāsikā). Hal ini disebabkan pañcasīla adalah merupakan panduan atau standar dasar dari norma-norma prilaku baik dari kehidupan. Jika semua orang dapat melaksanakan pañcasīla ini, dapat dipastikan akan tercapai kehidupan yang damai dunia ini. Oleh karena itu, pañcasīla dikenal sebagai "Pelindung dunia." Selain itu, pañcasila juga disebut sebagai "Nicca Sīla" yang berarti sila yang harus selalu dijaga atau dilaksanakan; atau "Garudadhamma Sīla" yang berarti sila yang harus selalu dijaga atau dilaksanakan dengan penuh hormat dan sungguh-sungguh.

Lima-sila ini terdiri dari:

\section{Pāṇātipātā veramaṇī sikkhāpadaì samādiyāmi.}

Aku bertekad melatih diri menghindari pembunuhan makhluk hidup.

2. Adinnādānā veraman̄ī sikkhāpadà̇ samādiyāmi.

Aku bertekad melatih diri menghindari pengambilan barang yang tidak diberikan.

3. Kāmesu micchācārā veramaṇī sikkhāpadaì samādiyāmi.

Aku bertekad melatih diri menghindari perbuatan asusila.

4. Musāvādā veramaṇī sikkhāpadà̇ samādiyāmi.

Aku bertekad melatih diri menghindari ucapan bohong.

5. Surā-meraya-majja-pamādațthānā veramaṇi sikkhāpadai் samādiyāmi.

Aku bertekad melatih diri menghindari minuman memabukkan hasil penyulingan dan atau fermentasi yang menyebabkan lemahnya kesadaran.

\section{Panatipata veramani sikkhapada samadiyami}

Aku bertekad akan melatih diri menghindari pembunuhan makhluk hidup. Umat Buddha seharusnya menghindari diri dari pembunuhan makhluk hidup. Kita tidak boleh membunuh baik dari hewan yang paling kecil sampai yang paling besar. 
Pembunuhan telah terjadi jika memenuhi lima faktor, yakni :

1. Ada makhluk hidup.

2. Mengetahui bahwa makhluk itu masih hidup.

3. Berniat untuk membunuh.

4. Melakukan usaha untuk membunuh.

5. Makhluk tersebut meninggal karena usaha itu.

Jika terdapat faktor dalam tindakan pembunuhan, maka telah terjadi pelanggaran sila pertama. Karena sila sangat berpengaruh pada perbuatan (kamma), dan kamma inilah yang akan membawa kemana kita akan terlahir kembali. Untuk itu hindarilah diri kita dari perbuatan pembunuhan. Semua makhluk pada dasarnya menginginkan kesejahteraan bagi semua makhluk. Akibat melakukan pemubunhan maklhuk hidup adalah tidak tenang, umurnya pendek, dan berpenyakitan.

Dalam Samyutta Nikaya (III, 15) Buddha mengajarkan bahwa "pembunuh melahirkan pembunuh". Di kisahkan seperti cerita dari keturunan Raja Bimbisara. Keturunan Raja Bimbisara ini adalah mereka yang membunuh ayahnya masing-masing. Salah satunya adalah anak dari Raja Bimbisara yaitu Raja Ajatasattu yang membunuh Raja Bimbisara atau ayahnya. Ini adalah kisah singkat mengenai pembunuh melahirkan pembunuh.

\section{Adinnadana veramani sikkhapada samadiyami}

Bertekad akan melatih diri menghindari dari pencurian. Dalam agama Buddha, mencuri adalah pelanggaran sila kedua. Buddha mengajarkan bahwa akibat mencuri akan membawa penderitaan bagi si pencuri itu sendiri. Hal ini diuraikan di dalam kitab Samyutta Nikaya (III, 15). Ketika beliau berkata kepada para bhikkhu bahwa manusia mencuri akan berakibat: "ia akan terus merampok/ mencuri, hingga saat tindakan tersebut menjadi penyebab kematiannya".

Jadi si pelaku itu akan terus mencuri, sebelum dia menyesal bahwa pencurian mengakibatkan dia terlahir di alam rendah. Untuk itu dia harus menyadari bahwa mencuri itu adalah perbuatan yang buruk serta melanggar sila. Akibat melanggar sila adalah si pelaku terlahir di alam menyedihkan (Apaya 4). 
Pencurian telah terjadi jika terdapat lima faktor yakni :

1. Suatu barang milik orang lain.

2. Mengetahui bahwa barang itu ada pemiliknya.

3. Berniat untuk mencurinya.

4. Melakukan usaha untuk mengambilnya.

5. Berhasil mengambil melalui usaha itu.

Berhasil melalui usaha itu adalah apabila barang itu telah berpindah dari tempat semula. Ketika seseorang mencuri dan tiba-tiba pemiliknya datang, dan kemudian ia mengembalikkan barang tersebut kepada pemiliknya, ia sudah dikatakan mencuri, karena barang tersebut sudah berpindah dari tempatnya. Pelanggaran sila berakibat sangat buruk, sesuai dengan kekuatan kehendak untuk mencuri, nilai barang yang dicuri dan tingkat kemajuan rohani pemiliknya. Jika kita tidak mau kehilangan apa yang kita miliki, kita tidak boleh mengambil barang milik orang lain.

\section{Kamesumicchacara veramani sikkhapada samadiyami}

Bertekad untuk menghindari diri dari perbuatan asusila. Menahan diri adalah hal yang sangat penting dalam hidup. Untuk itu harus menjaga perilaku sebaik mungkin, agar pelanggaran sila ketiga ini tidak muncul. Perilaku seksual banyak jenisnya, yakni, berzinah, perkosaan, dan perselingkuhan.

Suatu tindakan asusila telah terjadi bila terdapat lima faktor yang terdiri dari:

1. Orang yang tidak patut untuk disetubuhi

2. Mempunyai niat untuk menyetubuhi orang tersebut

3. Melakukan usaha untuk menyetubuhinya

4. Berhasil menyetubuhinya.

Mengenai orang yang tidak patut disetubuhi adalah wanita-wanita sebagai berikut:

1. Di bawah perlindungan ibunya (maturakkhita)

2. Di bawah perlindungan ayahnya (piturakkhita)

3. Dalam perlindungan ayah dan ibunya (matapiturakkhita)

4. Dalam perlindungan kakak perempuannya atau adik perempuannya (bhginirakhita) 
5. Dalam perlindungan kakak lelakinya atau dalam perawatan adik lelakinya (bhaturakkhita)

6. Dalam perlindungan sanak keluarganya (natirakkhita)

7. Dalam perlindungan orang sebangsanya (gotarakkhita)

8. Dalam perlindungan pelaksanaDharma (dhammarakkhita)

9. Yang sudah dipinang oleh raja atau orang-orang yang berkuasa (saparidanda)

10. Yang sudah bertunangan (sarakkheta)

11. Yang sudah dibeli oleh seorang lelaki, atau telah digadaikan oleh orangtuanya (dhanakkheta)

12. Yang tinggal oleh lelaki yang dicintainya (chandavisini)

13. Yang rela dikawini oleh lelaki karena mengharapkan harta benda (bhagavasini)

14. Yang rela dikawini oleh lelaki karena mengharapkan barang-barang sandang (patavansini)

15. Resmi menjadi istri seorang lelaki dalam suatu upacara adat istiadat (odapattagagini)

16. Yang menjadi istri seorang lelaki yang membebaskannya dari perbudakkan (abhatasumbatta)

17. Tawanan yang kemudian dikawini oleh seorang laki-laki (dhajabata).

18. Pekerja yang dikawini oleh majikannya (kammakaribhariya).

19. Budak yang kemudian dikawini oleh majikannya (dasibhari).

20. Yang menjadi istri seorang lelaki dalam jangka waktu tertentu (muhuttika).

Berhasil menyetubuhi adalah berhasil memasukkan alat kelaminnya ke dalam salah satu dari rahim, dubur dan mulut walaupun sedalam biji wijen. Pelanggaran ini berakibat buruk, yang berat dan ringan tergantung pada kekuatan yang mendorongnya dan cara pelaksanaannya, serta status atau tingkat rohani dari wanita yang bersangkutan, misalnya seorang bhikkhuni atau mereka yang telah mencapai kesucian. Buah kamma yang kita dapat, apabila kita melanggar sila ketiga yaitu kita tidak disenangi teman dan mempunyai pasangan hidup yang tidak disenangi orang lain.

\section{Musavada veramani sikkhapada samadiyami}

Bertekad akan melatih diri menghindari diri dari berbohong. Seorang umat awan hendaknya menghindari perkataan yang tidak benar dan selalu mengucapkan kata-kata yang sopan sehingga, di dalam hidup bermasyarakat akan tercipta suasana yang tenang, karena tidak ada kebohongan diantara semuanya.

Musavada telah terjadi jika terdapat empat faktor yakni :

1. Sesuatu atau hal yang tidak benar. 
2. Mempunyai niat untuk menyesatkan.

3. Berusaha untuk menyesatkan.

4. Orang lain jadi tersesat.

Dalam kehidupan sehari-hari hendaknya berbicara dengan benar dan gembira. Suatu perkataan itu mengandung makna dan bermanfaat sehingga orang yang mendengar akan senang dengan ucapan yang dilakukan.

Dalam Kakacupama Sutta Majjhima Nikaya 1, Buddha mengatakan bahwa, ucapan benar dapat terjadi apabila terdapat 5 syarat sebagai berikut:

1. Ucapan itu tepat pada waktunya

2. Ucapan itu sesuai kebenaran

3. Ucapan itu lembut

4. Ucapan itu bermanfaat

5. Ucapan itu penuh cinta kasih.

Ucapan benar akan menimbulkan kebijaksanaan, menciptakan perdamaian dan menghilangkan perpecahan. Ucapan yang tidak benar ini akan menimbulkan kamma buruk bagi pelakunya, akibatnya adalah tidak dipercayai oleh orang lain, dan menderita karena dia telah mengucapkan perkataan yang tidak benar. Untuk itu hindarilah ucapan berbohong dan selalu mengucapkan kata-kata yang benar dan bermanfaat.

\section{Surameraya majjapamadatthana veramani sikkhapada samadiyami}

Bertekad akan melatih diri dari menghindari minum minuman keras yang dapat melemahkan kesadaran. Hilangnya pengendalian terhadap kesadaran dapat mengakibatkan hilangnya pengendalian terhadap pikiran, ucapan dan perbuatan. Melanggar sila kelima ini kesadarannya hilang, dan dapat membahayakan dirinya sendiri.

Sila kelima ini telah dilanggar, bila terdapat lima macam faktor sebagai berikut:

1. Sesuatu yang merupakan sura, meraya, atau majja.
a. Ada niat untuk meminum, menggunakannya.
b. Meminum atau menggunakannya.
c. Timbul gejala-gejala mabuk. 
Tujuan pelaksanaan sila kelima adalah untuk melatih kesadaran terhadap segala hal yang dapat memperlemah pengendalian diri dan kewaspadaan. Dengan mengontrol pikiran dengan benar dan selalu waspada terhadap segala tindakan yang diperbuat. Untuk itu selalu waspada terhadap semua tindakan yang akan diperbuat.

\section{Delapan-Sila (Ațthasīla)}

Mereka yang ingin menjalankan praktik sila yang lebih mendalam, dapat melaksanakan latihan ațthasīla. Ațthasīla merupakan pengembangan dari pañcasīla. Atțhasīla dapat dilaksanakan setiap saat, tetapi pada kebanyakan orang hanya melaksanakannya pada hari uposatha. Hari uposatha adalah hari pelatihan diri atau berpuasa. Hari uposatha terjadi pada saat bulan terang, pada pertengahan antara bulan terang dan gelap, bulan gelap, dan pada pertengahan antara bulan gelap dan terang. Pada hari uposatha umat melaksanakan delapan-sila, maka delapan-sila ini dikenal juga sebagai uposatha sila.

Pelaksanaan delapan-sila ini lebih mengkondisikan seseorang untuk terhindar dari serangan objek-objek indera, sehingga akan mengurangi timbulnya pendambaan, nafsu, atau bahkan kesombongan yang diakibatkan kontak dengan objek-objek indera. Oleh karena itu, delapan-sila ini sangatlah cocok bagi para umat awam yang ingin atau sedang berlatih meditasi.

Delapan-sila ini terdiri dari:

1. Pāṇātipātā veramaṇī sikkhāpadà̇ samādiyāmi.

Aku bertekad melatih diri menghindari pembunuhan makhluk hidup.

2. Adinnādānā veramaṇ̄ sikkhāpadaì samādiyāmi.

Aku bertekad melatih diri menghindari pengambilan barang yang tidak diberikan.

3. Abrahmacariyā veramaṇi sikkhāpadà̇ samādiyāmi.

Aku bertekad melatih diri menghindari perbuatan tidak suci.

4. Musāvādā veramaṇī sikkhāpadaì samādiyāmi.

Aku bertekad melatih diri menghindari ucapan bohong.

5. Surā-meraya-majja-pamādaț̣̂̄ānā veramaṇ̄ sikkhāpadä̀ samādiyāmi.

Aku bertekad melatih diri menghindari minuman memabukkan hasil penyulingan dan atau fermentasi yang menyebabkan lemahnya kesadaran.

6. Vikāla-bhojanā veramaṇi sikkhāpadaì samādiyāmi.

Aku bertekad melatih diri menghindari makan makanan setelah tengah hari. 
7. Naccagīta-vādita-visūkadassanā-mālāgandha-vilepana-dhāraṇa-maṇdanavibhūsanațthānā veramaṇī sikkhāpadaṁ samādiyāmi.

Aku bertekad melatih diri menghindari menari, menyanyi, bermain alat musik, dan pergi melihat pertunjukkan yang merupakan rintangan bagi Latihan Mulia; memakai bungabungaan, wangi-wangian, dan barang-barang kosmetik untuk mempercantik diri.

8. Uccāsayana-mahāsayanā veramaṇi sikkhāpadà̇ samādiyāmi.

Aku bertekad melatih diri menghindari penggunaan tempat tidur dan tempat duduk yang tinggi dan besar (mewah).

\section{Penutup}

Peranan pancasila Buddhis dalam kehidupan sehari-hari sangat bermanfaat. Pada kenyataannya sekarang banyak umat Buddha yang moralitasnya turun. Selain moralitas mulai turun, mereka juga belum mengerti sepenuhnya tentang akibat pelanggaran pancasila Buddhis. Jika ingin menjalankan praktik sila yang lebih mendalam, dapat melaksanakan latihan ațthasīla. Ațthasīla merupakan pengembangan dari pañcasīla. Atțhasīla dapat dilaksanakan setiap saat, tetapi pada kebanyakan orang hanya melaksanakannya pada hari uposatha. Pelaksananaan Atṭasīla perlu lebih maksimal karena harus melatih diri melaksanakan 8 (delapan latihan). Delapan sila ini dikenal juga sebagai uposatha sila. Pelaksanaan uposatha sila terjadi pada tanggal 1, 8, 15 dan 23, menurut penanggalan bulan. Delapan-sila ini sangatlah cocok dilaksanakan bagi umat Buddha terutama dalam upaya mengembangkan meditasi.

\section{Daftar Pustaka}

Bhikkhu Joti Dhammo, 2003. Pancasila Buddhis dalam Etika-Sejarah, Teologi dan Etika Agama-Agama, Yogyakarta.

Bhikkhu Sikkhānanda. 2012. Sila, Penjelasan disertai Cerita. Tangerang.

J.R., A.G. Honig, 1992. Ilmu Agama Bagian I, Gunung Mulia, Jakarta,.

Maha Pandita Sumedha Widyadharma, 2003. Dhamma-Sari, Jakarta, Yayasan Dana Pendidikan Buddhis Nalanda.

Nanamoli \& Bodhi. 2013. Majjhima Nikaya. Jakarta. Dhammacitta Press.

2013. Paritta Suci, Kumpulan Wacana Pali untuk Upacara dan Puja. Jakarta. Yayasan Sangha Theravadha Indonesia. 